\title{
DESCARTES E A TECHNÉ MODERNA
}

Antônio José Nascimento ${ }^{1}$

\begin{abstract}
Resumo
O presente artigo analisa a contribuição de Heidegger para o entendimento de como a metafísica cartesiana da subjetividade concorreu para a concretização técnica do mundo, posto que essa posição metafísica se torna verdadeiramente conspícua para a nova liberdade do homem e para o modo de ser técnico da ciência moderna. Na representação matemática da natureza como objeto (ante)posto por um sujeito, o mundo então convertido em imagem, como pretende Heidegger, passa a constituir a essência da época moderna. Deveras, com sua redução a equações matemáticas, a res extensa é preparada para se transformar de matéria natural em produto da técnica. A centralidade do cogito, enquanto operador basilar da cognição calculadora, demarca o horizonte no qual tudo se desdobra como produto da vontade do homem, de sua projetualidade. Nesse sentido, a técnica assoma como manifestação instrumental dessa vontade, e seu caráter - o de ser uma técnica científica, uma tecno-loghia - está subtendido no enquadramento matemático do saber calculante da ciência que emerge da racionalidade estruturada pela ontologia cartesiana, destinada a servir de meio para o controle e domínio da totalidade do real.
\end{abstract}

Palavras-chave: Modernidade. Representação. Ego cogito. Cálculo. Técnica.

\section{DESCARTES AND MODERN TECHNE}

\begin{abstract}
This article analyzes Heidegger's contribution to the understanding of how the Cartesian metaphysics of subjectivity contributed to the technical realization of the world, since this metaphysical position becomes truly conspicuous for the new freedom of man and for the way of being technical of modern science. In the mathematical representation of nature as an object put forward by a subject, the world then converted into an image, as Heidegger intends, becomes the essence of the modern age. Indeed, with its reduction to mathematical equations, the res extensa is prepared to transform itself from natural matter into product of the technique. The centrality of the cogito, as the basic operator of calculating cognition, sets the horizon in which everything unfolds as a product of man's will, of his projectuality. In this sense, the technique appears as an instrumental manifestation of this will, and its character - that of being a scientific technique, a tecno-loghia - is subtended in the mathematical framework of the calculating knowledge of science that emerges from the rationality structured by the Cartesian ontology, destined to serve as a means for the control and mastery of the totality of the real.
\end{abstract}

Keywords: Modernity. Representation. Ego cogito. Calculation. Technique

1 Graduado em Ciências Econômicas pela Universidade Federal de Sergipe (1986), Mestre em Teoria Econômica (1994) pela UNICAMP (Universidade Estadual de Campinas) e Doutor em Filosofia pela Universidade de Évora. Atua como professor do quadro efetivo do Departamento de Economia da UFS. Email: ajntoinho@outlook.com. http://orcid.org/0000-0002-6970-0617. 


\section{Introdução}

É nos tempos modernos que se consuma o projeto de objetivação científica da natureza e de exploração técnica do mundo como forma específica de vigência da realidade que vigora, para Heidegger, como objetidade processável da representação processadora, em vista do que o homem se converte em sujeito e o mundo, por sua vez, em objeto.

Em virtude de seu caráter eminentemente tecnocientífico, a modernidade é sobretudo o evento do empoderamento do homem na fabricação do mundo, no sentido de que este agora se constitui como projetualidade - ou bem como imagem - posta aí como ob-jectus (Gegen-stand) por um sujeito autoinvestido na condição de regente da exposição dos entes. Nessa tomada de posse do mundo, aos entes suprime-se-lhes a pura presença como automanifestação para, em seu lugar, fazer-se valer o que pode ser trazido à 'presença' (Vorstellen) como resultado, unicamente, da deliberação de um subjectum.

Com efeito, o modo moderno de produzir o desvelamento dos entes já não é mais o da produção do mundo natural segundo suas próprias delimitações, e nem tampouco o da produção circunspecta, própria do modo originário de o humano estar no mundo com os outros (Mitsein) em sua humanidade, mas o da desmesura, o da prodigalidade concernente à vontade de poder da provocação tecnológica que conduz até mesmo o homem à objetificação.

Reduzido a mero recurso - ou a capital humano - do Gestell que o mobiliza, o humano assim funcionalizado desempenha-se, contudo, como principal componente do programa racionalizado de exploração dos entes como insumo, como matéria-prima desse ordenamento peculiar baseado no ciclo incessante do produzir pelo produzir internado na essência mesma da técnica, que, em sua fuga para a frente, afasta o homem da lembrança do ser.

Para a compreensão de como se chegou a isso, o presente artigo examina como Heidegger circunscreve o papel desempenhado pela metafísica cartesiana na constituição do mundo moderno (Neuzeit) que se realiza como imagem tecnologicamente processada. Ao fazer avançar o ente como objeto da 'representação' (Vor-stellung) posta por um subjectum alçado a regente de toda determinação, o que ao fim e ao cabo se leva a efeito com a ontologia cartesiana é o projeto de apropriação (tecno)científica do mundo agora convertido em realidade operacional da técnica. Afinal, enquanto método, a calculabilidade - o extenso mensurável de Descartes - é sempre um poder contar previamente com algo; ergo, é esquadrinhamento desafiador pertencente à essência metafísica da técnica.

\begin{tabular}{|l|l|l|l|l|}
\hline Qevista Dialectus & Ano 10 & n. 23 & Maio - Agosto 2021 & p. 66 - 82 \\
\hline
\end{tabular}




\section{1 - Descartes e a fundação da metafísica moderna}

Em sua exegese da modernidade, Heidegger (2013, p. 99) distinguiu a metafísica da subjetividade de Descartes como o acontecimento de maior envergadura dos novos tempos - o seu começo decisivo -, porquanto nela se consubstancia uma forma de expressão da liberdade humana historicamente sem precedentes. Coube a Descartes, diz Heidegger (2012a, p. 132), a tarefa de criar o fundamento metafísico para essa libertação, que o homem experimenta em sua decisão no tocante ao que deve ser sabido e na garantia da certeza de que sabe, "enquanto autodeterminação certa de si mesma" ou como o essencial dessa "liberdade reclamada como autocerteza".

Noutras palavras, a filosofia de Descartes cumpre o papel conspícuo de ser essa referência organizadora e mesmo fundadora da "nova liberdade" da época moderna, em que o homem se dá a lei a si próprio e estabelece o que é necessário e vinculante na representação de si e de sua essência. De ora em diante, "ser livre" passa a significar que, "em lugar da certeza da salvação que era critério de medida para toda a verdade, o homem põe uma certeza em virtude da qual e na qual alcança a certeza de si como daquele ente que se coloca a si mesmo como sua própria base"2 (HEIDEGGER, 2013, p. 636).

Descartes, realmente, protagoniza uma extraordinária reviravolta na tradição engendrada pelos gregos, ao tornar legítimo o artifício da dúvida que promove a varredura das convicções cristalizadas por todo um passado que ele próprio se incumbe agora de colocar em suspensão. Ao fim e ao cabo de seu itinerário, conforme indicação de Bornheim (1996, p. 99), “o nosso filósofo alcança por fím a certeza absoluta, o cogito, ponto de partida de toda edificação filosófica", e com a qual "a experiência absoluta já não coincide com a experiência do Absoluto", mas com o averiguável "em termos simplesmente humanos", por meio "do exercício da razão presa à sua própria imanência". Varrido, assim, o passado, "inventa-se o homem moderno".

No modo de ver de Touraine (1994, p. 60), a dominância do pensamento de Descartes na modernidade não se deve unicamente à sua condição de "arauto do racionalismo", mas sobretudo a ter podido fazer a modernidade "avançar com firmeza". Isso porque a herança de Descartes extrapola a mera descoberta do Método e das regras capazes de protegê-lo

2 Esta e todas as demais citações retiradas de textos aqui originalmente referenciados em espanhol, italiano e inglês foram por mim traduzidas. Outrossim, esclareço que optei por não reproduzir em rodapé, por uma questão de parcimônia, o original das muitas passagens citadas no interior dos parágrafos, exceção feita, entretanto, àquelas destacadas em margens próprias.

\begin{tabular}{|l|l|l|l|l|}
\hline Qovista Q Oialectus & Ano 10 & n. 23 & Maio - Agosto 2021 & p.66-82 \\
\hline
\end{tabular}


internamente contra o logro da experiência imediata. Através do cogito que entroniza o sujeito no controle da razão que é agora "experimentada na consciência do pensamento", o espírito humano está livre para esquadrinhar o ordenamento da natureza, decifrar suas leis e facultar ao homem, enfim, assenhorear-se do mundo natural da vida.

Como fundador da filosofia moderna, Descartes vai exprimir no cogito o arrimo que faltava à construção do domínio do homem sobre todo o ente ( $C f$. GALIMBERTI, 2010, p. 190). Evidentemente que a metafísica, agora subjetivada, continua a dominar. Todavia, muda - observa Galimberti (2010, pp. 190-191) - "a unidade de medida à qual a totalidade do ente deve referir-se para ser garantida, mas não muda a exigência de segurança, que se acentua e se torna mais rigorosa". Semelhante exigência de rigor é discernível, consoante indicação de Kobayashi (1996, p. 14), no emprego que Descartes realiza de sua metafísica como fundamento para a sua física, motivo pelo qual desenvolve suas ideias em recorrente referência à filosofia da natureza.

Maritain (2003, p. 44), contudo, não endossa a tese do protagonismo da filosofia da natureza de Descartes, porque a vê tão-somente como uma transferência para a ordem filosófica daquilo que já se vinha conformando como exigência do apparatus físico-matemático crescentemente empregado pela ciência emergente na intepretação da natureza sensível. Decididamente, pareceu-lhe que a filosofia mecânica da natureza de Descartes compreendia apenas "uma adaptação maravilhosamente servil da filosofia ao estado dinâmico das ciências e da pesquisa científica de sua época". De resto, aduziu que, como modelo de inteligibilidade fundado na interpretação quantitativa, a filosofia cartesiana apenas fornece uma explicação do funcionamento dos fenômenos em seu apelo à res extensa tomada a partir do observável e do mensurável, isto é, da quantitas das coisas aplicada à lógica identitária de compreensão dos fenômenos.

Para Heidegger ${ }^{3}$ (2013), diferentemente, ao transformar o homem em sujeito, e fazer dessa investidura o sustentáculo de uma nova mundividência, a metafísica cartesiana da subjetividade não somente confere ao homem um estatuto propriamente moderno, como também demarca o cunho da metafísica moderna. Até Descartes, a tradição metafísica consagrara que "todo ente, na medida em que é um ente, é compreendido como sub-iectum [...] e significa o que subjaz, o que está na base, e que desde si já se coloca adiante" (HEIDEGGER,

3 Notadamente nas seguintes seções: "El domínio del sujeto en la época moderna" [Die Herrschaft des Subjekts in der Neuzeit], "El cogito de Descartes como cogito me cogitare" [Das Cogito Descartes' als me cogitare] e "El cogito sum de Decartes" [Descartes' Cogito Sum].

\begin{tabular}{|c|c|c|c|c|}
\hline Qovista Dialectus & Ano 10 & n. 23 & Maio - Agosto 2021 & p. $66-82$ \\
\hline
\end{tabular}


2013, p. 635). Com Descartes, por conseguinte, processa-se a insólita conversão do "eu" humano em sujeito da metafísica da era moderna, a partir da qual, então, acrescenta Heidegger (2013, p. 635),

\begin{abstract}
A tradicional pergunta condutora da metafísica - o que é o ente? - se transforma [...] na pergunta pelo método, pelo caminho no qual, desde o homem mesmo e para ele, busca-se algo incondicionalmente certo e seguro, e se delimita a essência da verdade. A pergunta 'o que é o ente?' se transforma na indagação pelo fundamentum absolutum inconcussum veritatis, pelo fundamento incondicional e inquebrantável da verdade ${ }^{4}$.
\end{abstract}

\title{
2 - "O matemático" como enquadramento preabarcável da totalidade
}

Na instauração de sua metafísica, o expediente de Descartes consistiu em colocar "o matemático" como o fundamento mais elevado e absoluto para o ser do ente em geral. Nessa condição essencial do matemático como projeção, tem lugar a formulação axiomática originária e antecipadora do real como experiência disposta num ordenamento inteligível de princípios básicos. Assim, acrescenta Heidegger (1967, pp. 102-103), "se a matemática, no sentido de uma mathesis universalis, deve fundar e enformar a totalidade do saber, requer então a formulação de axiomas especiais", os quais, além de serem "absolutamente os primeiros, intuitivamente evidentes, em si e por si mesmos [...] precisam estabelecer antecipadamente, no que concerne à totalidade do ente, o que é o ente e o que ser significa, de onde e como a coisidade das coisas é determinada".

A definição cartesiana de uma posição essencialmente matemática dos entes não admite que algo como uma predeterminação vigente nas coisas mesmas se possa verificar. Resulta, então, que a proposição fundadora não poderia jamais ser uma proposição arbitrária qualquer, que não pudesse, mais que tudo, estar baseada em seu próprio fundamento. Tem de ser, pois, um princípio basilar absoluto, fonte de todo assentar, quer dizer, "uma proposição em

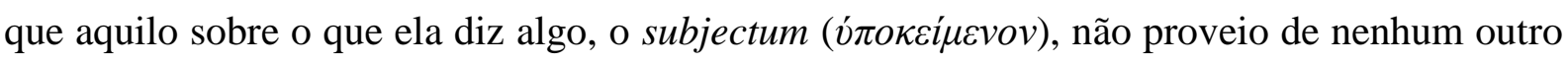
lugar" (HEIDEGGER, 1967, p. 103). Mais do que pugnar por uma lei fundamental para a natureza, de ora em diante o importante mesmo, em conformidade com Heidegger (1967), é o poder firmar-se da razão em seus próprios requerimentos, como fulcro de todo conhecimento e como tribunal de última instância para todas as determinações do ser, já que as coisas não devêm mais em sua coisidade.

\footnotetext{
4 "La tradicional pregunta conductora de la metafísica - ¿qué es el ente?- se transforma [...] en pregunta por el método, por el camino en el cual, desde el hombre mismo y para él, se busca algo incondicionalmente cierto y seguro y se delimita a la esencia de la verdad. La pregunta «¿qué es el ente?» se transforma en pregunta por el fundamentum absolutum inconcussum veritatis, por el fundamento incondicional e inquebrantable de la verdade".
}

\begin{tabular}{|c|c|c|c|c|}
\hline Revita Dialectus & Ano 10 & n. 23 & Maio - Agosto 2021 & p. $66-82$ \\
\hline
\end{tabular}


Na metafísica de Descartes, para alguma coisa ser há que ter sido posta ou presentificada como objeto por um sujeito seguro de si próprio, resguardado em sua confiança na representação matemática outorgante de um domínio prévio da essência (calculada) dos entes. Esse, desde logo, o traço marcante de que se reveste a metafísica cartesiana para o que Heidegger identificaria como um passo decisivo rumo à tecnologia moderna.

Vattimo (1991, p. 87), a propósito, ressaltou que, não obstante se costume associar a configuração do mundo moderno a um expediente da ciência e da técnica, o certo é que a identificação do ser das coisas com a certeza posta por um sujeito, enquanto mentalidade, esteve na raiz do processo mediante o qual se gestou e se robusteceu a atitude mobilizadora que consistiu em submeter o ser dos entes a uma deliberação da vontade humana.

De uma maneira com a qual Heidegger decerto teria concordado, Spengler, em $A$ Decadência do Ocidente, explorou como poucos o caráter da mudança de orientação do mundo matemático cartesiano em comparação com o antigo, o grego. Com apreensão perspicaz e elaboração refinada da questão do pensamento matemático e de seus mundos numéricos, Spengler (1966, p. 66) faz-nos ver que as bem determinadas propriedades da matemática não são exatamente uma construção abstrata e universal, imutável e idêntica de uma espécie de $a$ priori sintético kantiano, mas antes "a expressão de um sentimento do universo [e] princípio de um ordenamento do produzido" no centro de uma cultura. Por isso - diz ele -, "há [...] mais de uma matemática". A estrutura interna da geometria euclidiana, por exemplo, é inteiramente distinta da cartesiana.

Com efeito, "o matemático antigo não conhece mais do que o que vê e toca. Onde cessa a visibilidade limitada e limitante, objeto único de seus pensamentos, ali termina sua ciência” (SPENGLER, 1966, p. 88). A relação, portanto, dessa matemática com as coisas visíveis é marcante, diferentemente do que se dá com a abstração numérica do cálculo infinitesimal moderno-cartesiano, que "desfaz o conceito de magnitude, da dimensão sensível, transmitida pelos textos antigos e a tradição árabe, e o substitui pelo valor variável relativo das posições no espaço" (SPENGLER, 1966, p. 80). Noutras palavras,

o número antigo, constante, foi dissolvido no número variável. A geometria, convertida em analítica, desfez todas as formas concretas. Em lugar do corpo matemático, em cuja imagem rígida se determinam certos valores geométricos, a análise pôs relações abstratas de espaço que já não são aplicáveis aos fatos das intuições sensíveis reais ${ }^{5}$ (SPENGLER, 1966, p. 93).

5 “[...] el número antiguo, constante, ha quedado disuelto en el número variable. La geometría, convertida en analítica, ha deshecho todas las formas concretas. En lugar del cuerpo matemático, en cuya imagen rígida se

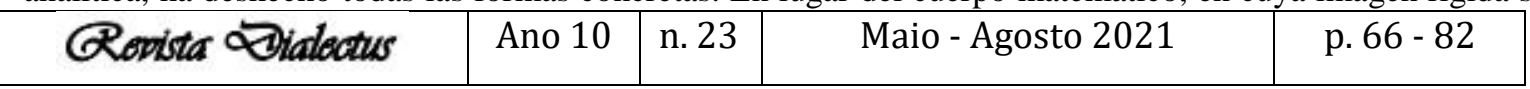


A reviravolta assim processada no matemático importou, nas palavras de Rüdiger (2014, p. 105),

\begin{abstract}
em sua crescente predominância sobre o pensar, a subordinação da medida concreta ao cálculo abstrato e, com ela, a enunciação do princípio da razão. As coisas passaram a ser determinadas cada vez menos pelo que é próprio delas mesmas, tornando-se, em vez disso, o que objeta ao subjacente, isto é, à razão [...] O resumo é que a matemática deixou de ser arte liberal para se tornar o veículo da ciência moderna da natureza.
\end{abstract}

No sentido forte mesmo de ascensão e predomínio da representação matemática como figura distintiva do pensamento que orienta o saber operatório da modernidade, a metafísica de Descartes, bem se vê, foi fulcral na constituição da ratio cognoscendi do mundo da vida moderna. Como indicação, ainda, dessa mudança de orientação do novo que agora governa, cumpre-se, para além do bem e do mal, a moderna provocação técnica da natureza em que pese encontra-se ela mesma inscrita no continuum da linhagem histórica do pensamento metafísico ocidental.

Como quer Heidegger (2012a, p. 99), o caráter moderno do pensar é já “a execução e a consequência de um modo determinado do estar-aí histórico, da respectiva posição-de-fundo diante do Ser em geral e do modo como o Ente enquanto tal se manifesta”. Daí que, in summa: “o novo mundo da nova época tem seu fundamento próprio ali onde toda história busca seu fundamento essencial: na metafísica, isto é, numa nova determinação da verdade do ente, em sua totalidade, e da essência da verdade” (HEIDEGGER, 2013, p. 639).

\title{
3 - O ego cogito como fundamentum
}

De fato, pode-se falar metafisicamente num continuum. Sem embargo, há, em Descartes, uma determinação inteiramente nova do que se enuncia em comparação com o oferecido pela tradição, notadamente no que concerne ao percurso histórico da verdade, entendida, originalmente, entre os antigos gregos, como aletheia ou atributo manifestativo da natureza, e depois como adaequatio, isto é, como correspondência entre o intelecto e a coisa, para, finalmente, traduzir-se como certitudo - a certeza subjetiva cartesiana. Desta feita, é como fundamentum absolutum e, ao mesmo tempo, inconcussum da certeza da veritatis que o subjectum cartesiano dota a modernidade de uma peculiaríssima maneira de conhecer e de

hallan ciertos valores geométricos, el análisis ha puesto relaciones abstractas de espacio que ya no son aplicables a los hechos de las intuiciones sensibles actuales".

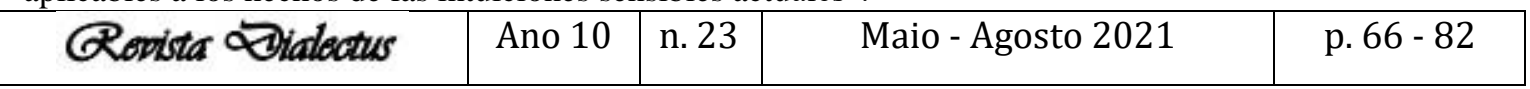


operar sobre a matéria-mundo agora convertida em realidade objetiva das coisas $(C f$. HEIDEGGER, 2013, p. 868).

A partir do que Zimmerman (1990, pp. 171-172) designou por subjectivistic turn encetada por Descartes, "a humanidade começou a arrogar-se a si mesma o papel de Deus, de fundamento fundador, o produtor de todas as coisas", e desse modo concorreu para tornar possível a projetualidade humana fundada exclusivamente nos critérios da certeza do sujeito cognoscente. E foi justamente essa certeza de si mesmo do ego cogitador que Descartes empregou como base ontológica para todas as coisas. Com isto, a partir dele, conforme já assinalado, para algo vir a ser teria que estar implicado no ser objeto de um sujeito autodeterminado, certo de si mesmo, vale dizer, "nada realmente é a menos que possa ser representado (vorgestellt)". E assim, apoiada na incondicionalidade do subjectum, é como se configura a metafísica da época moderna, para o que foi determinante - torne-se a ressaltar - a constituição mesma da metafísica cartesiana.

No entender de Heidegger, Descartes se antecipa assim na apreensão das necessidades essenciais dos novos tempos, fornecendo-lhes uma direção segura com vistas à mundanização (no sentido mesmo de um conhecimento mundano) da verdade dos entes e ao estabelecimento igualmente seguro da essência dessa verdade. Nessa perspectiva, o próprio Heidegger (2013, p. 640) se pergunta, então, de que maneira Descartes empreende esse feito antecipador do fundamento metafísico da nova liberdade e de que espécie, afinal, teria de ser este fundamento. Sua resposta:

De uma espécie tal que o homem, a cada momento, pudesse, a partir de si mesmo, assegurar-se daquilo que garante o proceder para todos os fins e representação humanos. Sobre esta base, o homem teria que estar certo de si mesmo, isto é, do asseguramento das possibilidades de seus propósitos e representações ${ }^{6}$.

O ego cogito (ergo) sum, que Heidegger (2012a, p. 133) qualificou como a "proposição condutora" de Descartes, "é este algo certo que forma o fundamento e dá o fundamento" com o qual se estabelece uma nova determinação da essência do conhecimento e da verdade agora transmutada em certeza. Mas não só: com ela Descartes também empreende o que Heidegger (2013, p.650) interpreta como uma determinação inteiramente nova da essência do matemático.

6 "De una especie tal que el hombre en todo momento pudiera asegurarse desde sí mismo de aquello que asegura el proceder a todo propósito y a toda representación humanos. Sobre esta base, el hombre tenía que tener certeza de sí mismo, es decir, del aseguramiento de las posibilidades de sus propósitos y representaciones".

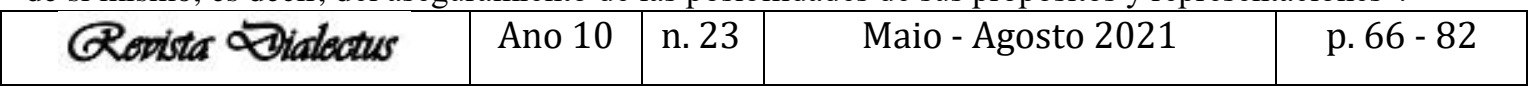


Ao fazer do cogito sum uma "proposição fundamentada [Grundsatz] e um princípio" - fundamentum e principium -, o que em rigor se tem aí é "o subjectum no sentido do representar que se representa" (HEIDEGGER, 2013, p. 655). Por isso é importante ter-se na devida conta o que Descartes quis realmente expressar, segundo Heidegger (1967, p. 107), com a sua proposição ego cogito (ergo) sum, porque, se bem entendida, permite que se ultrapasse a argumentação silogística que, por exemplo, apanha o ergo como significando, conclusivamente, que o sum é uma consequência do pensar, quando, pelo contrário, é o seu fundamentum. Isto posto, em vez de se tomar o ergo conclusivamente, o mais apropriado é tomá-lo como indicação de um "querer dizer por si mesmo" (HEIDEGGER, 2013, p. 650), que é o que precisamente tem lugar no imediato da imbricação do sum que se determina como ego cogito - na conexão, portanto, e não como conclusão, e assim “o eu sou não é inferido do eu represento, senão que o eu represento é, por sua essência, o que eu sou" (HEIDEGGER, 2013, p. 650).

Habitualmente traduzida como 'penso (duvido), logo existo (sou)', para todos os efeitos a referida proposição enseja que se possa depreender do enunciado eu penso o consequente eu existo. Baseando-se numa tal inferência, ficaria então pacificamente demonstrada a existência do eu-aí. Heidegger, contudo, empenhou-se em mostrar, conforme já indicado, que interpretá-la nesses termos, sem mais, como se silogística fosse, equivaleria a incorrer em simplificação do real alcance de seu significado, ao qual apenas se pode aceder se se tiver clareza acerca do que Descartes entende por cogito, cogitare. O problema todo decorre, diz Heidegger (2013, p. 642), de a proposição em si revestir-se de um "princípio supremo", e assim, como "primeiro princípio", como um estatuir-se originário, vê-se, pois, dispensada de demonstração por ser evidente em si mesma. Tal significa que "a prova, a experimentação, o ensaio ou ainda a crítica, não fazem parte do método cartesiano: a institucionalização do método passa a operar como um grau zero fundacional” (HERNÁNDEZ, 2010, p. 248).

Trata-se, pois, nesse nível de instanciação - conforme esclarece-nos Leopoldo e Silva (1996, p. 355) -, do processo de subjetivação que "leva à absolutização do sujeito no plano do conhecimento", por meio de cuja "efetivação metódica da busca do fundamento" o sujeito é a um só tempo posto como existência e como fundamento. Por conseguinte, “como o que está em questão é a fundação do conhecimento, a existência e a essência lógica tornam-se necessariamente indiscerníveis", face ao "teor epistêmico exclusivo" resultante da autodeterminação do sujeito em sua "função fundamentadora". Daí se poder dizer que "o sum se determina como ego cogito" (HEIDEGGER, 2013, p. 651).

\begin{tabular}{|c|c|c|c|c|}
\hline Q & Ano 10 & n. 23 & Maio - Agosto 2021 & p. 66 - 82 \\
\hline
\end{tabular}


Em linhas gerais, deve estar claro que a transformação do homem num tipo proeminente de subjectum, num tipo novo do que subjaz em si mesmo, como fundamentum da verdade, conduz, de acordo com Heidegger, ao domínio da subjetividade processadora da representação que, na metafísica de Descartes, instaura o mundo como objetualidade do sujeitorepresentante que se vê assim representado. Com efeito, "na medida em que todo re-presentar remete o objeto que se há de re-presentar, e o objeto representado, ao homem re-presentante, o homem re-presentante resulta 'correpresentado' dessa maneira peculiar” (HEIDEGGER, 2013, p. 645), isto é, como sujeito que se referencia na representação do objeto em relação ao qual, como sujeito, é já referência a si representativa, autoposicionado como substantia (HEIDEGGER, 2012b, p. 159).

\section{4 - A realidade como representatividade}

Em Die Zeit des Weltbildes (O Tempo da Imagem do Mundo), a questão do representar é reposta numa vinculação mais estreita com a objetivação e o cálculo, em cuja chave o pensar - diz Heidegger (2012a, p. 133) - "é re-presentar, referência representadora ao que é representado (idea enquanto perceptio)". Na representação, é mister o assegurar-se de que aquilo que se vem a pôr diante do sujeito, e a partir dele, seja posto em segurança. Para tanto, "este assegurar tem de ser um calcular, porque só a calculabilidade garante, à partida e constantemente, estar certo do que se está para representar". E o representar - acrescenta Heidegger (2013, p. 870) -, que já não é a mera percepção do que-está-presente, também “já não é o pôr-se-a-descoberto para [...] mas o agarrar e conceber de [...] Não é o que-está-presente que vigora", no sentido da exclusividade de seu domínio como actus purus, mas o ataque que prepondera na representação, porque “o representar é um avançar [...] uma objetivação que doma. Representar é ob-jectivação, é cogitatio. O ente já não é o que-está-presente, mas só o que está posto em frente no representar, o que é ob-jectivo [Gegen-ständinge]" (HEIDEGGER, 2012a, p. 133).

Nesse plano da relação sujeito-objeto, no qual o mundo é identificado como a totalidade dos objetos de representação ou como universo representado que é trazido à presença e assim disposto perante o sujeito numa relação objetivante, o "representar" -salienta Giacoia Jr. (2009, p. 72) - "é reapresentar", isto é, um "dispor objetivamente os entes para a apreensão teórica, de modo a extrair deles um saber científico que enseja controle e disponibilização para operações técnicas”.

\begin{tabular}{|c|c|c|c|c|}
\hline Govista Dialectus & Ano 10 & n. 23 & Maio - Agosto 2021 & p. 66 - 82 \\
\hline
\end{tabular}


Similarmente, Zimmerman (1990, p. 172) sugere que, para Heidegger, "representar significa não tomar a coisa tal como ela se apresenta a si mesma, mas antes re-apresentá-la no sentido de retratá-la em termos flexíveis para os padrões e propósitos do sujeito que representa". Por sua vez, Inwood (1999, p. 185) apanha, nesse âmbito, o que "é concebido como o explicável e susceptível de ser produzido do ente-representado", ressaltando a articulação que subiste aí entre o cartesianismo e a tecnologia referidos como figuras da modernidade.

Assim situado, observa Heidegger (2012b, p. 160), "todo o ente é agora ou o que é efetivamente real enquanto objeto, ou o que é atuante enquanto objetivação na qual se forma a objetividade (Gegenständlichkeit) do objeto" representado na objectivação que o remete ao ego cogito. No interior da subjetividade do ente - ou da subjetividade do subjectum que, "enquanto certeza absoluta de si, é a ciência" -, o homem levanta-se para instaurar o mundo como objetivação e a natureza, como objeto da técnica. Neste levantamento - Heidegger (2012c, p. 293) o diz de forma taxativa - "a própria Terra apenas se pode mostrar como objeto do ataque que se instala como objetivação incondicionada no querer do homem. A natureza aparece por todo o lado, porque disposta a partir da essência do ser, como o objeto da técnica".

Como elemento fundamental do representar que é um produzir, sobressai, então, o levar a efeito, o efetuar consistente da realidade efetiva - que Kant, mais tarde, compreenderá como objetividade do objeto. Pensada metafisicamente, portanto, em sua representatividade, a realidade "não significa jamais que o real seja um produto anímico-espiritual ou mesmo o efeito de uma atividade representativa, e, por conseguinte, algo de que se está diante apenas como uma construção psíquica”, à semelhança do que se dá com uma imitação ou cópia da realidade. Muito pelo contrário. No processo que consiste em 'colocar' (stellen) o mundus como objeto (ob-jectus, Gegen-stand) diante (vor) de um sujeito que o 'representa' (vor-stellen), e assim o reduz, como objetualidade, a uma imagem subjetiva, representação é, para todos os efeitos, esclarece Galimberti (1999, p. 313),

a antecipação mental das condições perante as quais qualquer coisa pode revelar-se
na modalidade antecipadamente aguardada. Na base desta manifestação não está mais,
como para os antigos, o originário manifestar-se da natureza, mas o projeto
matemático do homem desvelado pela antecipação mental do cogito que, assentando
as condições de manifestação da natureza, resolve esta última na própria
representação ${ }^{7}$.

7 “'...] l'anticipazione mentale delle condizioni, in presenza delle quali, qualcosa può rivelarsi nelle modalità in cui era anticipatamente atteso. Alla base di questa manifestazione non è più, come per gli antichi, l'originario manifestarsi della natura, ma il progetto matematico dell'uomo dischiuso dall'anticipazione mentale del cogito che, ponendo le condizioni delle modalità di presentazione della natura, risolve quest'ultima nella propria rappresentazione".

\begin{tabular}{|c|c|c|c|c|}
\hline Rovista Dialectus & Ano 10 & n. 23 & Maio - Agosto 2021 & p. $66-82$ \\
\hline
\end{tabular}


É desse modo - aduz Heidegger (2013, pp. 869-870) - que sai à luz, como presença dentro do representar, o que impera na metafísica da essência do ser como a essência mesma da realidade que, com isso, perde sua ambiguidade ao adquirir caráter de objetividade na representatividade posta como actualitas do ens creatum, porque, convém notar, pensados a partir do que involucra essa nova essência da realidade efetiva, "o representar humano mesmo e o homem representante [...] são aqui mais constantes, mais reais e mais entes que todos os entes restantes".

Indubitavelmente, essa é uma questão crucial para o que aqui envolve a compreensão tanto do começo quanto do próprio acabamento da metafísica da subjetividade moderna na metafísica da vontade de poder que caracteriza a consolidação do domínio global da técnica. A partir de Descartes, como temos podido notar, o significado de que passa a se revestir o 'presenciar', como aquilo que é agora a certeza da realidade como actualitas, como manifestação do operar que é determinativo do pôr, do colocar, do instalar o 'real' como 'realidade' deliberada pelo subjectum, deixa de ser, pois, autenticamente falando, o que verdadeiramente subjaz, para se converter no agente da redução da totalidade das coisas a si mesmo.

Nisso, em suma, de o homem fundar-se a si mesmo como medida para todas as coisas e de conferir à verdade um caráter, primeiro, de correção ou de adequatio da coisa à proposição, e, depois, o de certeza de si do sujeito, ocorreu de se perder de vista, na demarcação do ser do ente enquanto coisa, a consideração mesma para com o ser-da-coisa em sua coisidade, para com o ser-em-si-mesmo, irredutível quer ao enquadramento conceitual, quer à representação pelo cálculo configurador da presença. Na presentidade do ser-para-um-outro, que é tomada não como automanifestação e constância do que perdura no autodesvelamento, mas como colocação injuntiva de uma determinação, faz-se tabula rasa do que persiste de nãodesvelado no que se mostra através da representação que, no fundo, está implicada num fazer violência ao caráter de coisa das coisas.

\section{5 - Substantia, calculum e domínio técnico do mundo}

Ao descortinar o nexo que em Descartes articula o cogitare ao calculum como forma constringente de trazer os entes à presença, Heidegger explicita como essa forma de desvelar o mundo, enquanto objetualidade, prepara e robustece as disposições para o advento da era da técnica e do predomínio do pensamento calculador. Em Sein und Zeit (Ser e Tempo),

\begin{tabular}{|c|c|c|c|c|}
\hline Q & Ano 10 & n. 23 & Maio - Agosto 2021 & p. $66-82$ \\
\hline
\end{tabular}


no enfrentamento que promove da questão relativa à ontologia cartesiana da apreensão do mundo, Heidegger (2014, p. 110) é enfático no tocante à necessidade de se promover a destruktion dessa ontologia, que considera errada em seu modus de tomar o ser dos entes como “imediatamente à mão". Em suas palavras,

O ente que Descartes trata de definir de um modo ontológico fundamental com a extensio é um ente apenas se se deixa descobrir num processo que passa por um ente intramundano e 'à mão' imediatamente [...] Descartes dá uma errada definição ontológica do mundo ${ }^{8}$.

Ora bem, o errado, em questão, tem a ver, antes de mais nada, com o fato de que subsiste no interior da noção de substantia em Descartes uma inadmissível ambiguidade de fundo. Recorrendo a uma passagem dos Principia de Descartes, de acordo com a qual "por substância não podemos entender outra coisa senão um ente que é de tal modo que para ser não necessita de nenhum outro ente”, Heidegger (2014, pp. 107/109) pondera que

definir a substância por meio de um ente substancial é a razão da ambiguidade do termo. O pensado é a substancialidade, se se a compreende partindo de uma propriedade ôntica da substância. O ontológico é ultrapassado pelo ôntico, e o termo substância evoca imediatamente um significado ontológico semelhante ao ôntico, em geral com uma desconexa significação ôntico-ontológica ${ }^{9}$.

Iniludivelmente, da perspectiva de Heidegger, substantia, no homem, guarda relação com a existencialidade, e não, por assim dizer, com a fixidez do que em Descartes se deixa assimilar como extensão. Heidegger (2014, p. 233) assim o diz: "a impossibilidade de conceber o ente na forma do ser do 'ser-aí' pela realidade ou substancialidade é o que temos enunciado com a tese: a substância do homem é a existência". Já o ponto de partida de Descartes, como se tem podido entrever, concebe a forma de ser do ente, enquanto extensio, como o próprio ser do mundo, e ademais estabelece que a via de acesso a este ente somente se pode dar através do conhecimento físico-matemático, o qual "passa por ser aquela forma de apreensão dos entes que pode estar certa, em todo momento, de possuir com segurança o ser dos entes apreendidos nela (HEIDEGGER, 2014, p. 110).

8 "El ente que Descartes trata de definir de un modo ontológico fundamental con la extensio es un ente sólo se deja descubrir en un processo que pasa por un ente intramundano y 'a la mano' inmediatamente [...] Descartes da una errada definición ontológica del mundo".

9 “[...] definir la sustancia por medio de un ente sustancial estriba la razón de la ambigüedad del término. Lo mentado es la sustancialidad, pero se la comprende partiendo de una propiedad óntica de la sustancia. Lo ontológico es suplantado por lo óntico y el término substantia tan pronto funciona con una significación ontológica como con una significación óntica, aunque las más de las veces con una vagarosa significación óntico-ontológica”.

\begin{tabular}{|l|l|l|l|c|}
\hline Rovista Dialectus & Ano 10 & n. 23 & Maio - Agosto 2021 & p. $66-82$ \\
\hline
\end{tabular}


Descartes, no que lhe respeita, não consente em que o modo de ser dos entes intramundanos possa derivar deles mesmos, porque "sabe muito bem que os entes não se mostram imediatamente em seu verdadeiro ser" (HEIDEGGER, 2014, p. 111), e por esse motivo Descartes - acentua Heidegger - prolata sua própria medida de ser, que prescreve ao mundo como verdadeira valendo-se da matemática como expediente privilegiado de apreensão do sentido ontológico de mundo. Contudo, não se trata de que o tenha conseguido porque a matemática, per se, faculta uma tal configuração ontológica; ao contrário, é em vista de uma orientação ontológica fundamental de que parte -a do ser como presença constante/calculávelque pôde, em resumo, distinguir o conhecimento matemático de um modo bastante satisfatório $^{10}$.

Sem isso - vale dizer, sem essa perspectiva da representação processável que põe o ente na conta de coisa segura, estável, objetiva e portanto manipulável - não se compreende a especificidade da técnica na efetuação do mundo que se descortina no âmbito da metafísica de Descartes, porque, de uma vez por todas, essa metafísica é não apenas e tão-somente o começo da modernidade, mas, mais que isto, é o sustentáculo da da produção técnica do ser que se mostra inicialmente na representação da nova humanidade moderna. Enquanto aspecto fulcral da nova era, a conversão da verdade em certeza fez emergir uma "cultura" (história do ser) propiciadora do que redundaria na dominação planetária da técnica como expressão da "vontade de poder" incondicional do homem.

Em vista disso, a 'realidade efetiva' [Wirklichkeit] passa a corresponder ao que o homem estabele como segurança de si mesmo e de seu operar estruturador do autoasseguramento da humanidade no alargamento irrefreado (e ipso facto perigoso) de suas realizações e vivências. O próprio Descartes (1998, p. 62), quanto a isso, foi taxativo, ao propor que

é possível alcançar o conhecimento que seria útil à vida, e que, em vez dessa filosofia especulativa ensinada nas escolas, é possível encontrar uma filosofia prática, através da qual, conhecendo a força e as ações do fogo, água, ar, as estrelas e os céus e todos os demais corpos que nos cercam, tão claramente quanto conhecemos as artes dos nossos artesãos, poderíamos ser capazes, da mesma forma, de utilizá-las para todos os fins para os quais são adequados e, assim, tornarmo-nos senhores e possuidores da natureza ${ }^{11}$.

10 Ao ver de Pöggeler (1990, p. 40), "He [Descartes] finds in a 'mathematical' cognition the mode of access to the Being of the world -not out of a preference for mathematics, but rather because thinking as a 'seeing' has always been oriented toward the constantly presente-at-hand, and mathematics above all knows what is always there, what remains constant and outlives all change".

11 " $[. .$.$] it is possible to arrive at knowledge that would be very useful in life and that, in place of that speculative$ philosophy taught in the schools, it is possible to find a practical philosophy, by means of which, knowing the force and the actions of fire, water, air, the stars, the heavens, and all the other bodies that surround us, just as

\begin{tabular}{|l|l|l|l|c|}
\hline Rovista Dialectus & Ano 10 & n. 23 & Maio - Agosto 2021 & p. $66-82$ \\
\hline
\end{tabular}


Tratou-se, sabidamente, da investidura numa forma especial de poder, um empoderamento acima de tudo peculiar à época da supremacia tecnológica tornada metafisicamente possível como história moderna. História, principalmente, do que Thiele (1998, p.108) chamou de "domínio possessivo" do mundo como corolário do subjetivismo cartesiano, e que Heidegger (2013, p. 637) assinalou como “o essencial dar poder ao poder [...] como realidade fundamental na história da época moderna e como essa história”.

\section{Considerações finais}

Enfim, pôde-se ver que a ontologia cartesiana constitui, no fundamental, um ataque contra a pura presença do ser no aberto, o qual é trazido para o modo de desocultação no disposto pela representação objetificadora que reveste a modernidade de um estatuto muito peculiar: o da história do ser como domínio da verdade assente na certeza de si do sujeito. Com efeito, assoma aí, como tarefa crucial da metafísica de Descartes, a libertação do homem experimentada como liberdade do subjectum coroado como senhor das determinações essenciais de sua humanitas.

Mediante o conhecimento objetivo da natureza, assegurado pelo ego cogito ergo sum da metafísica cartesiana da subjetividade, o caminho preparatório para o domínio tecnológico do homem sobre todo o ente fica franqueado, enquanto aberto de possibilidades tecnocientíficas de controle calculado do mundo. De fato, é no imperialismo planetário da técnica que o sugjetivismo do homem alcança sua plenitude. Em realidade, contudo, não se está diante, como parece, do incondicionado do desenvolvimento do homem em suas possibilidades mais autênticas de ser, mas de algo remetido ao autodesenvolvimento como tal da técnica que é mobilizadora do homem como recurso.

\section{Referências}

BORNHEIM, Gerd. Sobre o estatuto da razão. In: NOVAES, A. (org) A crise da razão. São Paulo: Companhia das Letras, 1996, pp. 189-204.

distinctly as we know the various skills of our craftsmen, we might be able, in the same way, to use them for all the purposes for which they are appropriate, and thus render ourselves, as it were, masters and possessors of nature".

\begin{tabular}{|c|c|c|c|c|}
\hline Qovista Dialectus & Ano 10 & n. 23 & Maio - Agosto 2021 & p. 66 - 82 \\
\hline
\end{tabular}


DESCARTES, René. Discourse on method and meditations on first philosophy. Translated by Donald A. Cress. 4th ed. Indianapolis, Indiana: Hackett Publishing Company, Inc, 1998.

GALIMBERTI, Umberto. Psiche e techné: l'uomo nella età della técnica. Milão: Feltrinelli, 1999.

GALIMBERTI, Umberto. Il tramonto dell'occidente: nella lettura di Heidegger e Jaspers. 5. ed. Milano: Feltrinelli, 2010.

GIACOIA JUNIOR, Oswaldo. Heidegger urgente: introdução a um novo pensar. São Paulo: Três Estrelas, 2009.

HEIDEGGER, Martin. What is a thing. Translated by W. B. Barton Jr \& Vera Deutsch. Indiana: Gateway Editions, 1967.

HEIDEGGER, Martin. O tempo da imagem do mundo. Tradução de Alexandre F. de Sá. In: Caminhos de floresta. Lisboa: Fundação Calouste Gulbenkian, 2012a.

HEIDEGGER, Martin. O conceito de experiência em Hegel. Tradução de Helder Lourenço. In: Caminhos de floresta. Lisboa: Fundação Calouste Gulbenkian, 2012b.

HEIDEGGER, Martin. A palavra de Nietzsche "Deus morreu". Tradução de Alexandre F. de Sá. In: Caminhos de floresta. Lisboa: Fundação Calouste Gulbenkian, 2012c.

HEIDEGGER, Martin. Nietzsche (Vol. único). Traducción de Juan Luis Vermal. Barcelona: Editorial Planeta, 2013.

HEIDEGGER, Martin. EI Ser y el tiempo. Traducción de José Gaos. 2. ed. Buenos Aires: Fondo de Cultura Económica, 2014.

HERNÁNDEZ, Alejandro. Descartes: el giro subjetivista o el señorío de la razón. In: ASSALONE, E. \& MISSER, L. (orgs). El giro subjetivista de la filosofía moderna. Mar del Plata: Ediciones Cátedra de Filosofía Moderna, 2010.

INWOOD, Michael. A Heidegger dictionary. Oxford: Blackwell Publishers Ltd, 1999.

KOBAYASHI, Michio. A filosofia natural de Descartes. Tradução de Maria J. B. Reis. Lisboa: Instituto Piaget, 1996.

LEOPOLDO E SILVA, Franklin. Ética e Razão. In: NOVAES, A. (org.), A crise da razão. São Paulo: Companhia das Letras, 1996, pp. 351-365.

MARITAIN, Jacques. A filosofia da natureza. Tradução de Luiz Paulo Rouanet. São Paulo: Loyola, 2003.

PÖGGELER, Otto. Martin Heidegger's path of thinking. Translated by D. Magurshak \& S. Barber. Atltantic Highlands: Humanities Press International, Inc: 1990.

RÜDIGER, Francisco. Martin Heidegger e a questão da técnica. Porto Alegre: Sulina, 2014.

\begin{tabular}{|l|l|l|l|l|}
\hline Qevista Dialectus & Ano 10 & n. 23 & Maio - Agosto 2021 & p. 66 - 82 \\
\hline
\end{tabular}


SPENGLER, Oswald. La decadencia de occidente: bosquejo de una morfologia de la historia universal. Traducción de: Manuel G. Morente. Madrid: Espasa-Calpe, 1966.

THIELE, Leslie P. Martin Heidegger e a política pós-moderna: meditações sobre o tempo. Tradução de Ana Matoso Mendes. Lisboa: Piaget, 1998.

TOURAINE, Alain. Crítica da modernidade. Tradução de Fátima Gaspar e Carlos Gaspar. Lisboa: Piaget, 1994.

VATTIMO, Gianni. Introduzione a Heidegger. 7. ed. Roma-Bari: Laterza, 1991.

ZIMMERMAN, Michael. Heidegger's confrontation with modernity: technology, politics, art. [Ebook]: Indiana University Press, 1990.

\begin{tabular}{|l|l|l|l|l|}
\hline Rovista Dialectus & Ano 10 & n. 23 & Maio - Agosto 2021 & p. 66 - 82 \\
\hline
\end{tabular}

